\title{
Physical modelling of consolidation behaviour of a composite foundation consisting of a cement-mixed soil column and untreated soft marine clay
}

\author{
J.-H. YIN and Z. FANG (2006). Géotechnique 56, No. 1, 63-68
}

\author{
J.-C. Chai, K. Onitsuka and S. Hayashi, Saga University, \\ Japan
}

The writers have presented the results of a well-controlled laboratory model test on the improvement of soft clay with deep cement mixing (DCM) columns, which certainly contribute to understanding the consolidation mechanism of improvement of composite subsoil with DCM columns. Regarding the value of hydraulic conductivity $k$ of a DCM column, we wish to make a comment/discussion.

The test results show that the excess pore pressure dissipation rate in the model DCM column was faster than that in the surrounding soft clay, and the writers explained this as being due to the fact that the column had a higher $k$ value than the surrounding unimproved soft clay, and so the column worked as a drain. Although this phenomenon is certainly a factor, we consider that the faster dissipation can be explained in another way: that is, the column accelerated the consolidation process due to its higher stiffness, which resulted in a higher coefficient of consolidation rather than a higher $k$ value. Basically, the initial $k$ value of a DCM column should not be much different from that of the unimproved soil.

It is generally agreed that the $k$ value of a soil is influenced mainly by its void ratio $e$, and by the size and shape of pores. For clayey soils, $k$ is usually related to $e$ (e.g. Taylor, 1948). When cement is mixed into a saturated clayey soil, there is not much change in its $e$ value or, therefore, in its $k$ value. Yamadera (1999) conducted laboratory consolidation tests on samples of reconstituted Ariake clay (a very soft clay deposit in Saga, Japan) and of Ariake clay mixed with $5 \%$ cement (by dry weight), and calculated $k$ values from the consolidation test results. The $e-k$ relationship is given in Fig. 11. It can be seen that, for a given $e$ value, the two samples almost gave the same $k$ value.

There are two possible reasons why the $k$ value of a DCM column should be larger than that of the unimproved soil. One is that, during the consolidation process, if the unimproved soil has more (compressive) volumetric strain, its $e$ value and therefore its $k$ value will be smaller than that of the DCM column. The other is that, during shearing, if the DCM column dilates or fails, its $k$ value will increase (Yu et al., 1999). For the test reported by the writers, an equal vertical strain condition was applied, and therefore the first reason is not applicable. The second reason is applicable only after the column failed. However, for an actual project, DCM columns are not designed to fail under working conditions.

The above argument can be demonstrated as follows. The model test reported by the writers was simulated by finite element analysis (FEA) under the condition that the DCM column and the surrounding unimproved marine clay have the same $k$ value but different stiffnesses. The unimproved marine clay was modelled by the Modified Cam clay model (Roscoe \& Burland, 1968), and the DCM column was

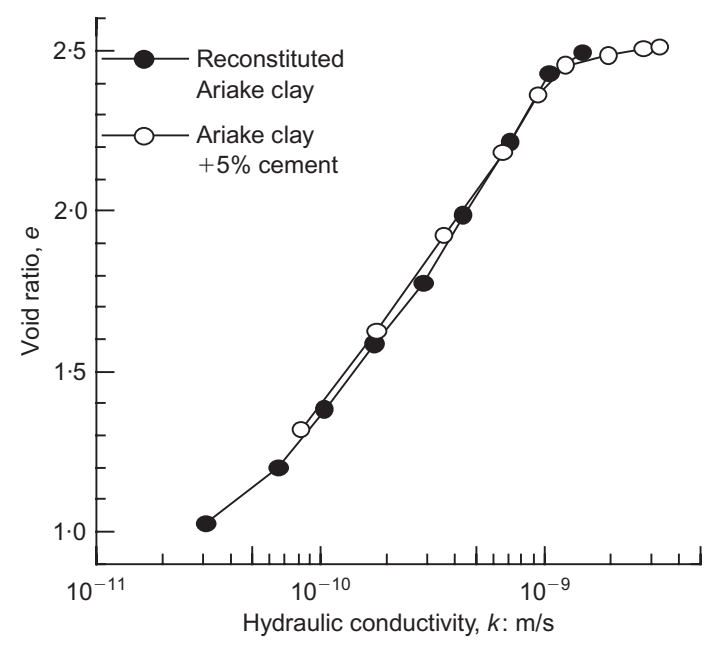

Fig. 11. Relationship between hydraulic conductivity and void ratio (data from Yamadera, 1999)

represented as a bilinear elastic material obeying the MohrCoulomb failure criterion (softening of the column after failure was not considered). All parameters adopted are listed in Table 2. As the writers did not report the detailed mechanical properties of the samples, except for the initial void ratio (calculated from the water content), all other parameters were assumed. To estimate the Young's modulus $E$ of the column, unconfined compression test results of cement-treated Hong Kong clay reported by Yin (2001) were referred to. An unconfined compressive strength $q_{\mathrm{u}}$ of $800 \mathrm{kPa}$ was assumed, and $E$ was taken as $89 q_{u}$ (Yin, 2001). To match a failure deviator stress of $800 \mathrm{kPa}, C=400 \mathrm{kPa}$ and $\phi^{\prime}=0$ were adopted. The unimproved marine clay forming the model ground was reconstituted under a vertical stress of $20 \mathrm{kPa}$. In the overconsolidated state, with the parameters given in Table 2 and a vertical effective stress of $10 \mathrm{kPa}$, a value of constrained modulus $D$ of about $1500 \mathrm{kPa}$ can be evaluated. In this case, the ratio of the constrained modulus of the DCM column to that of the unimproved marine clay is about 52, which is larger than the value of 44.1 reported by the writers. However, this value depends on the initial effective vertical stress adopted for evaluating $D$ for the unimproved marine clay. It is considered that at least the adopted values are within common sense.

Although the analysis is not intended for back-fitting the model test results, the calculated time-load-settlement curve is compared with the test data in Fig. 12 to show the general performance of the FEA. The radial excess pore pressure distributions under a total vertical stress of $20 \mathrm{kPa}$ are compared in Fig. 13. The analysis results indicate that, for an elapsed consolidation time of less than $2 \mathrm{~h}$, the excess pore pressure at the point near the column is almost the 
Table 2. Adopted parameters

\begin{tabular}{l|c|c|c|c|c|c|c|c|c|c}
\hline Soil & $E: \mathrm{MPa}$ & $v$ & $\lambda$ & $\kappa$ & $M$ & $E_{0}$ & $k: \mathrm{m} / \mathrm{s}$ & $C: \mathrm{kPa}$ & $\begin{array}{c}\phi^{\prime}: \\
\text { degrees }\end{array}$ & $\begin{array}{c}\sigma_{\mathrm{vm}}^{\prime} \\
(\mathrm{kPa})\end{array}$ \\
\hline $\begin{array}{l}\text { Column } \\
\text { Unimproved }\end{array}$ & $71 \cdot 2$ & $0 \cdot 2$ & - & - & - & $2 \cdot 3$ & $5 \times 10^{-10}$ & 400 & 0 & - \\
\hline
\end{tabular}

$E$, Young's modulus; $\nu$, Poisson's ratio; $\lambda$, slope of consolidation line in $e: \ln p^{\prime}$ plot; $\kappa$, slope of unloading-reloading line in $e: \ln p^{\prime}$ plot; $M$, slope of critical state line in $q: p^{\prime}$ plot ( $q$ is deviator stress, $p^{\prime}$ is effective mean stress); $e_{0}$, initial void ratio; $k$, hydraulic conductivity; $C$ and $\phi$, cohesion and internal friction angle in effective stress; and $\sigma_{\mathrm{vm}}^{\prime}$, initial yielding stress in vertical direction.
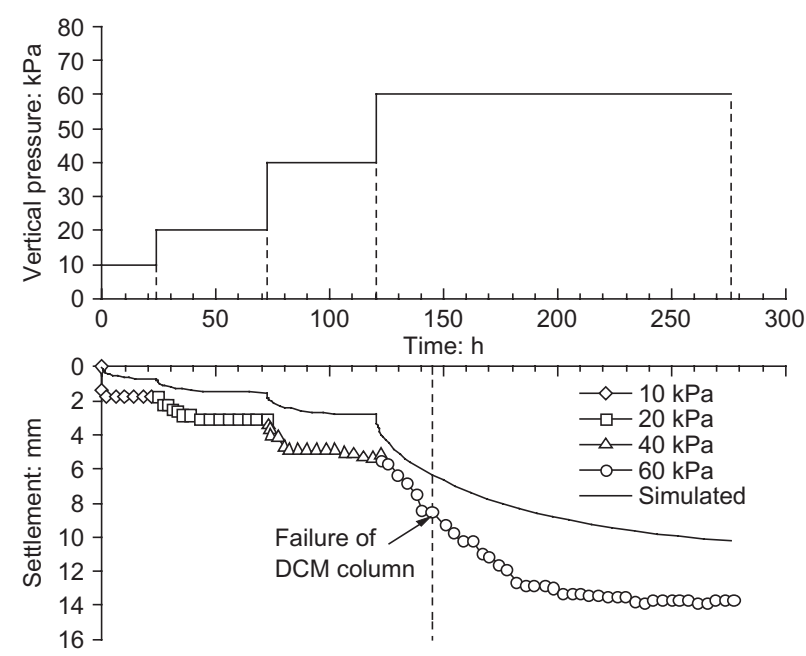

Fig. 12. Comparison of measured and simulated settlementtime-load curves

same as or higher than that at the points away from the column, which is different from the test data. When applying a load to composite model ground improved with a DCM column, the column will carry more load and initially generate more excess pore pressure. From this point of view, the analysis results are reasonable. Another factor is that, for the model test, the column was inserted into a pre-drilled hole, and the contact condition between the column and the surrounding soil might not be perfect, which could influence the amount of excess pore pressure generated in the surrounding soil as well as its dissipation rate. However, when the elapsed consolidation time is larger than $2 \mathrm{~h}$, the numerical results gradually show the same tendency as the test data: that is, the values of excess pore pressure reduce toward the column. This illustrates that a DCM column can accelerate the consolidation process of the composite subsoil even if it has the same $k$ value as that of the unimproved surrounding soil. In the paper, the radial distance of the piezometer points given in Fig. 1 and Figs 6 and 7 are different. We consider the information in Fig. 1 is more reliable, and used it for plotting Fig. 13. For a total vertical stress of $40 \mathrm{kPa}$, the analysis showed the same tendency as for the $20 \mathrm{kPa}$ case (no test data reported). However, for a total vertical stress of $60 \mathrm{kPa}$, the analysis does not yield the same tendency as for the 20 and $40 \mathrm{kPa}$ cases. This is because the DCM column failed at this stage, and the coefficient of consolidation is reduced to $1 \%$ (arbitrarily assumed) of its original value, so that it cannot act as a consolidation accelerator. However, for the model test, after the column failed there might be cracks formed in the column, which could serve as drainage paths.

\section{Authors' reply}

The authors would like to thank the discussers for their interest in our work and their discussion on our paper. It is helpful to us for improving the quality of information

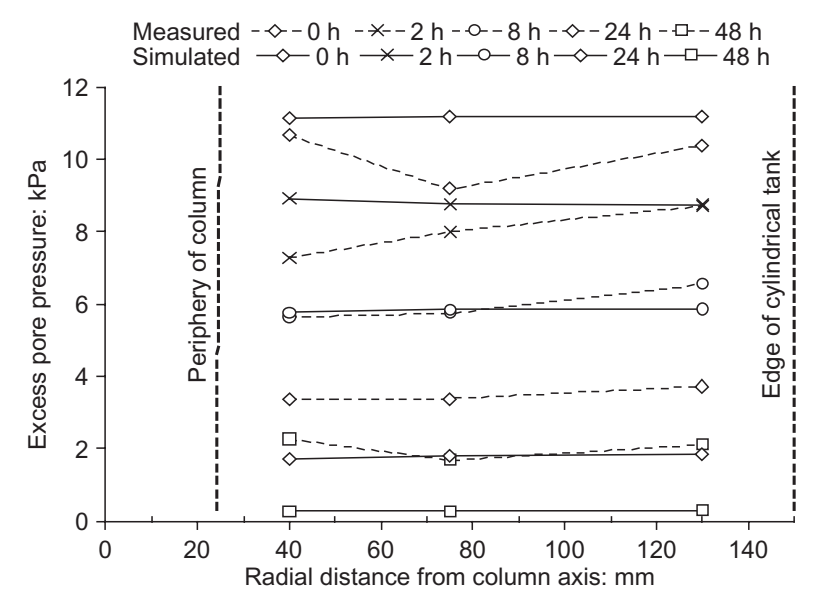

Fig. 13. Comparison of excess pore pressure distribution under a total load of $20 \mathrm{kPa}$

dissemination and for understating the consolidation phenomenon of a composite foundation consisting of a cementmixed soil column and untreated soft marine clay.

The authors would like to report that the excess pore water pressure (EPWP) responses in the DCM column were not measured in this model test. According to the recorded EPWP responses in the surrounding soil, it was concluded then that the column might have worked as a vertical partial drainage in the model test. In the paper, the authors considered that the main reason could be the $k$ value of the DCM column being higher than that of the surrounding unimproved soft clay. However, the discussers have explained that the slightly faster consolidation around the DCM column was due to the higher stiffness of the column, the permeability of which could be the same as that of the untreated soil. The authors appreciate these insightful comments, and agree that the higher stiffness of the DCM column has a higher coefficient of consolidation if the permeability of the DCM is the same as that of the soil.

In our model test, the coefficient of permeability of the DCM column, $k_{\mathrm{c}}$, was taken as being larger than that of the surrounding soil, $k_{\mathrm{s}}$. This assumption has been validated by oedometer tests carried out by Cheung (2003). The results showed that $k_{\mathrm{c}}$ ranged from 10 to 40 times $k_{\mathrm{s}}$. The discussers presented the hydraulic conductivity of Ariake clay and cemented Ariake clay, and reported that the initial value of $k_{\mathrm{c}}$ should be approximately the same as $k_{\mathrm{s}}$ for untreated soils. Because of the different soils and cement mixing conditions used, in reality the findings reported by different researchers on the permeability of cement-treated soils could be different. A summary of data collected about the permeability of cement-mixed soils is presented in Table 3. This table indicates that the permeability of cement-mixed soils is mostly larger than that of the untreated soils. In the practical conditions, possible cracks and fissures in the DCM columns could result in an increase in the permeability of the columns. 
Table 3. A list of some studies on the permeability of cement-mixed soils

\begin{tabular}{|c|c|c|}
\hline Reference & $\begin{array}{l}\text { Description of soils and cement } \\
\text { treatment }\end{array}$ & Relationship between $k_{c}$ and $k_{s}$ \\
\hline $\begin{array}{l}\text { Terashi \& Tanaka } \\
\text { et al. }(1981 \mathrm{c})\end{array}$ & $\begin{array}{l}\text { A summary on cement mixed } \\
\text { soils in Japan }\end{array}$ & $\begin{array}{l}\text { The treated clay is not regarded } \\
\text { as a drainage medium }\end{array}$ \\
\hline Kawasaki et al. (1981) & $\begin{array}{l}\text { Toyko Bay soil: laboratory and } \\
\text { in situ testing }\end{array}$ & $k_{\mathrm{c}} \approx 1 / 100 k_{\mathrm{s}}$ \\
\hline Yamadera (1999) & Ariake clay: $A_{\mathrm{w}}=5 \%$ & $k_{\mathrm{c}} \approx k_{s}$ \\
\hline Lorenzo (2001) & $\begin{array}{l}\text { Bangkok clay: } w_{i}=200 \% \text {, } \\
250 \% ; A_{\mathrm{w}}=5 \%, 8 \%, 10 \% \text {, } \\
15 \%\end{array}$ & $k_{\mathrm{c}} \approx 5-100 k_{\mathrm{s}}$ \\
\hline Cheung (2003) & $\begin{array}{l}\text { Hong Kong marine clay: } w_{i}= \\
80 \% ; A_{\mathrm{w}}=15 \%\end{array}$ & $k_{\mathrm{c}} \approx 10-40 k_{\mathrm{s}}$ \\
\hline Chew et al. (2004) & $\begin{array}{l}\text { Singapore marine clay: } w_{i}= \\
120 \% ; A_{\mathrm{w}}=20 \%, 30 \%, 50 \%\end{array}$ & $k_{\mathrm{c}} \approx 40 k_{\mathrm{s}}$ \\
\hline
\end{tabular}

It is considered that the influence of the contact condition between the DCM column and the untreated soil on EPWP should not be large. The small gap between the DCM column and the surrounding soil existed during the installation of the DCM column in our test. This gap was filled with cement grout immediately afterwards, which was not reported in detail in the paper. After the model test was completed, the DCM column was extruded from the soil, as shown in Fig. 14. It can be seen from the figure that some clay has adhered to the DCM column, which suggests a good contact between the DCM column and the surrounding soil.

The stiffness of the DCM column appears to have a small

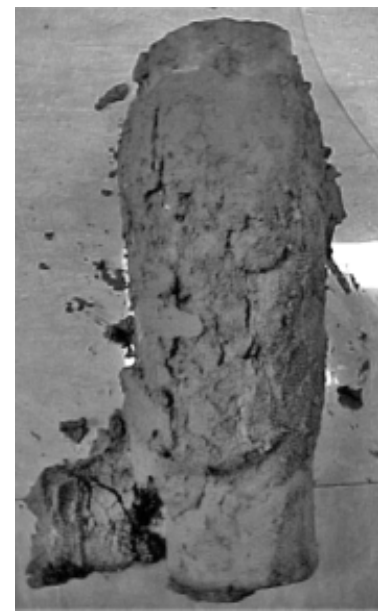

Fig. 14. Post-test DCM column impact on the radial drainage behaviour. The discussers have explained that the DCM column could have accelerated the consolidation process owing to its higher stiffness, which resulted in a higher coefficient of consolidation, rather than being due to a higher $k$ value. A finite element analysis was also performed by the discussers to support this statement. The authors acknowledge that higher stiffness of the column may affect the consolidation and responses of EPWP in the soils.

In order to understand the consolidation of the soil around a DCM column and the effects of the permeability of the DCM column, two finite element analyses with consideration of the interface between the DCM column and the soil have recently been performed by the authors. All material parameters used in the finite element analyses are determined

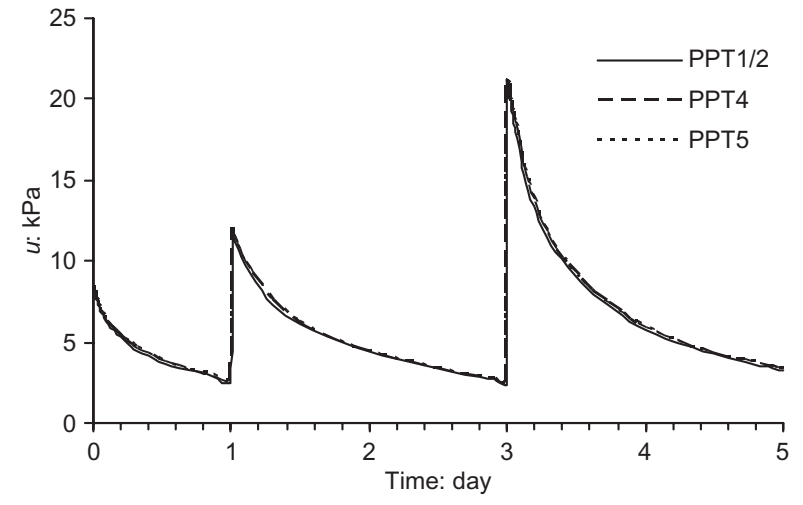

Fig. 15. Computed EPWPs at PPTs embedded in radial direction when $k_{\mathrm{c}}=\boldsymbol{k}_{\mathrm{s}}$

Table 4. Parameters used in the finite element analysis

\begin{tabular}{|c|c|c|c|c|c|c|c|c|c|c|c|c|}
\hline \multicolumn{2}{|c|}{ Material } & $\begin{array}{l}\text { Material } \\
\text { model }\end{array}$ & $E^{\prime}: \mathrm{MPa}$ & $v$ & $\lambda$ & $\kappa$ & $M$ & $e_{0}$ & $k: \mathrm{m} /$ day & $c^{\prime}: \mathrm{kPa}$ & $\phi^{\prime}$ & $\sigma_{\mathrm{vm}}^{\prime}: \mathrm{kPa}$ \\
\hline \multicolumn{2}{|l|}{ Clay } & $\mathrm{MCC}$ & - & $0 \cdot 3$ & $0 \cdot 23$ & 0.048 & $1 \cdot 2$ & $1 \cdot 80$ & $2 \cdot 0 \times 10^{-4}$ & - & 30 & $10 \cdot 0$ \\
\hline \multirow[t]{2}{*}{ DCM } & Case 1 & MC & 175 & $0 \cdot 3$ & - & - & - & $2 \cdot 17$ & $2 \cdot 0 \times 10^{-4}$ & 425 & 40 & - \\
\hline & Case 2 & $\mathrm{MC}$ & 175 & $0 \cdot 3$ & - & - & - & $2 \cdot 17$ & $4.0 \times 10$ & 425 & 40 & - \\
\hline \multicolumn{2}{|l|}{ Sand } & $\mathrm{MC}$ & $6 \cdot 5$ & $0 \cdot 25$ & - & - & - & $1 \cdot 8$ & $0 \cdot 1$ & $0 \cdot 2$ & 34 & - \\
\hline
\end{tabular}

$E^{\prime}$ and $v$ are elastic parameters, Young's modulus and Poisson's ratio; $\lambda$ is the slope of the consolidation line in the $e: \ln p^{\prime}$ plot; $\kappa$ is the slope of the unloading-reloading line in $e: \ln p^{\prime} \operatorname{plot} ; M$ is the slope of the critical state line in the $q: p^{\prime}$ plot; $e_{0}$ is the initial void ratio; $k$ is hydraulic conductivity; $c^{\prime}$ and $\phi^{\prime}$ are the effective cohesion and internal friction angle; and $\sigma_{\mathrm{vm}}^{\prime}$ is the initial yielding stress in the vertical direction. 


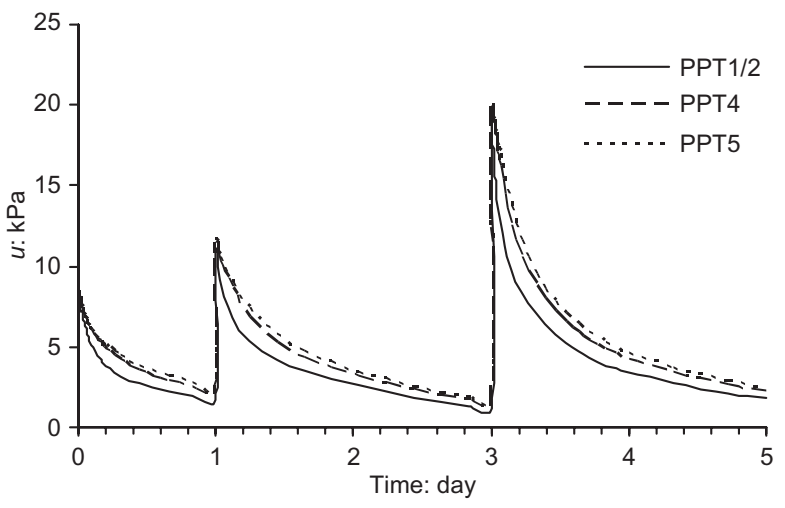

Fig. 16. Computed EPWPs at PPTs embedded in radial direction when $k_{\mathrm{c}}=20 k_{\mathrm{s}}$

from laboratory tests and are listed in Table 4. The computed results are shown in Figs 15 and 16. It can be seen from the two figures that the permeability of the DCM column has a large influence on the radial drainage behaviour in the soil. As shown in Fig. 16, no pronounced radial dissipation of pore water pressure can be observed for the case of $k_{\mathrm{c}}$ equal to $k_{\mathrm{s}}$ for our model test. However, this conclusion may not be extended to other cases, because the properties of the soil and the cement-mixed soil columns might be different for different cases.

\section{REFERENCES}

Cheung, H. Y. (2003). Properties and behaviour of soft Hong Kong marine clays improved by mixing with cement. Final year project report, BEng. thesis, Hong Kong Polytechnic University.

Chew, S. H., Kamruzzaman, A. H. M. \& Lee, F. H. (2004). Physicochemical and engineering behaviour of cement treated clays. J. Geotech. Geoenviron. Engng, 130. No. 7, 69-706.

Kawasaki, T., Suzuki, Y. \& Suzuki, Y. (1981). On the deep mixing chemical mixing method using cement hardening agent, Technical Research Report 26. Takenaka, Japan, pp. 13-42.

Lorenzo, G. A. (2001). A new compressibility model and finite element simulation on deep mixing method (DMM) application. $\mathrm{PhD}$ thesis, Asian Institute of Technology, Thailand.

Roscoe, K. H. \& Burland, J. B. (1968). On the generalised stressstrain behavior of 'wet' clay. In Engineering plasticity (edited by J. Heyman and F.A. Leckie), pp. 535-609. Cambridge: Cambridge University Press,

Taylor, D. W. (1948). Fundamentals of soil mechanics. New York: John Wiley \& Sons Inc.

Terashi, M. \& Tanaka, H. (1981c). On the permeability of cementand lime-treated soils. Proc. 10th Int. Conf. Soil Mech. Found. Engng, Stockholm 4, 947-948.

Yamadera, A. (1999). Microstructural study of geotechnical characteristics of marine clays. $\mathrm{PhD}$ dissertation, Saga University, Japan. 